\title{
Countering The Rise in Covid-19 Related Procrastination: An Intervention Study
}

\author{
Dr. Shyamolima Ghosh Choudhury ${ }^{1}$, Ananya $^{2}$, Simran Katoch ${ }^{3}$, Tanishqa $^{4 *}$
}

\section{ABSTRACT}

The lockdown due to Covid-19 has propelled a lot of individuals to procrastinate more and deviate from their usual standards of well-being. Procrastination becomes unhealthy for the youth as it involves a harmful delay of tasks that turns into dysfunction. A total of 27 individuals in the 18-25 age group met the sampling criteria and are selected to undergo various interventions for three weeks. The underlying assumption is that the lockdown is related to an increase in procrastination due to numerous factors. The present study is a pre and post design to understand how the interventions made a difference. Lay's General Procrastination Scale (1986) is used along with a brief qualitative interview to assess the results. The research hypothesis suggests that helpful interventions lead to a decrease in Procrastination. Results show $100 \%$ decrease in procrastination levels with significance beyond 0.001 level at the end of interventions, hence, the hypothesis is proved. The study confirms that simple interventions such as mindfulness, physical activity, meditation can be applied to effectively tackle procrastination and enhance well-being.

Keywords: Procrastination, COVID-19 Lockdown, Intervention, Mindfulness, Physical Activity, Well-Being, Youth, Gratitude Journals, Lay's General Procrastination Scale (1986)

$\mathrm{T}$ The pandemic came as a shock to all individuals as they had to drastically change their style of living. The lockdown has brought everyone's lives to a standstill and its sudden nature has led to a lack of activities. Educational institutions were shut down during this period and the level of face-to-face interactions decreased. Earlier, young adults were engaged in college activities, assignment submissions, jobs, internships and other hobbies but due to the lockdown, they were left with nothing to do. When work and education shifted from the offline to an online mode, the youth found it difficult to cope with these changes. At such a time, individuals are bound to face more stress, anxiety, and uneasiness. It also made individuals vulnerable to not doing things or prolonging things such as cleaning their room, taking a bath, academic work, and other activities. However, when individuals prolong tasks for an unhealthy period of time, it takes the form of

\footnotetext{
${ }^{1}$ Assistant Professor, Department of Psychology, Gargi College, University of Delhi, India

${ }^{2}$ Student, Gargi College, University of Delhi, Delhi, India

${ }^{3}$ Student, Gargi College, University of Delhi, Delhi, India

${ }^{4}$ Student, Gargi College, University of Delhi, Delhi, India

*Corresponding Author
}

Received: June 05, 2021; Revision Received: July 25, 2021; Accepted: August 14, 2021

(C) 2021, Ghosh Choudhury S., Ananya, Katoch S. \& Tanishqa; licensee IJIP. This is an Open Access Research distributed under the terms of the Creative Commons Attribution License (www.creativecommons.org/licenses/by/2.0), which permits unrestricted use, distribution, and reproduction in any Medium, provided the original work is properly cited. 


\section{Countering The Rise in Covid-19 Related Procrastination: An Intervention Study}

procrastination. Psychologists say that it is a conceptual representation of the dysfunction of capacities that are important for coping with tasks that accumulate on a daily basis. When individuals procrastinate, they waste time and miss opportunities, (Milgram, 1991).

Clarry Lay (1986), a prominent psychologist and the creator of the General Procrastination Scale (GPS) defined procrastination as "a time-related gap between intended and enacted behavior."

A renowned definition of procrastination was given by Milgram (1991), which involved four aspects of procrastination: (1) behavior be that results in postponement; (2) substandard behavior; (3) involving a task that is important to the procrastinator and; (4) leading to a state of emotional turmoil. He proposed a typological theory that established that individuals who are high on procrastination also experience behaviors of pessimism, repression, and anxiety. On the other hand, people who are low on procrastination, feel upset while delaying tasks and tend to display such behaviors less.

Procrastination was extensively investigated by Milgram, Sroloff and Rosenbaum in 1988. Their classic study indicated that procrastination is positively correlated to the unpleasantness of the task and the belief that one does not possess the motivation to do that task. The nature of all tasks is such that they require basic skills of decision making and faith in those choices, due to this reason individuals low on self-esteem and high on selfdefeating behaviours tend to procrastinate more, (Ferrari, 1993).

The pandemic has been a time of unpredictability. When an individual doesn't know what tomorrow holds, it adds to their stress and propels them not to complete their daily chores, (Chen and $\mathrm{Qu}, 2017)$. It creates a vicious cycle for the individuals wherein they get weaker, psychologically and physiologically, since they are not able to cope with the pending tasks. Such circumstances can lead to weaker emotional states, poor physical health and decreased well-being, (Totsi, 2012).

However, there are simple solutions to the issue at hand. Numerous studies have made use of mindfulness to tackle and significantly reduce the procrastination levels for working professionals and college students. Established literature depicts the inverse nature of being mindful and procrastination, (Dionne, 2016 \& Cheng et al, 2019). Mindfulness can also play a significant role in curbing the detrimental psychological and physiological effects of procrastination related stress and anxiety to increase well-being, (Sirois and Totsi, 2012). Mindfulness in turn also adds to the self-esteem of an individual by being aware and generating a sense of acceptance that was absent before, (Dionee, 2016).

Gratitude journals and high self-esteem are directly correlated. Thus, acknowledging and being grateful can improve decision-making and time management skills and in turn lead to lower levels of procrastination, (Lin,2015).

The ability to perform a task also involves physical agility and energy. Individuals who exercise and remain active tend to have a more optimistic outlook towards life due to their lifestyle. Being able to allot time to physical activity also inculcates the skill of time management and proactiveness. Thus, procrastination and physical activity are also inversely correlated, (Codina, Pestana, Valenzuela, et al, 2020). 
A lot of the studies mentioned above provide a base for the interventions. Innumerable studies establish a connection between mindfulness and the decrease in procrastination. Dionne (2016) conducted a study using acceptance and mindfulness as variables to reduce procrastination among college students. According to the results, such interventions helped in reducing procrastination and also increased mindfulness. Another study conducted by Cheung et al. (2019) examined the relationship between mindfulness and procrastination in 339 college students and concluded that procrastination and mindfulness are inversely related and thus, it is important to cultivate mindfulness in order to reduce procrastination. Lastly, a study conducted by Sirois and Tosti (2012) established that procrastination had a significant effect on the individual in terms of stress and weaker physical health. However, the study also established how mindfulness mediates these negative effects. Low mindfulness may lead to poor emotional states and weaker well-being.

Physical activity was also used as an intervention in the study to reduce procrastination among the participants. According to a study conducted by Codina, Pestana, Valenzuela, et al. (2020) to understand the connection between procrastination and physical activity, individuals who engage in more and more exercise have an optimistic perception about the quality of their life in the domains of physical and psychological health. The study shows how this perception is linked to lower levels of procrastination. In addition to that, the research also focused on how trying to give time to physical activity helps the individual understand time management and consciously allot time to activities.

Young adults are continuously going through emotional and psychological turmoil, at such a time the burden of academic pressure, physiological changes, and hormonal evolution doesn't do them any favors. This excess stress and uncertainty also create a vicious cycle of procrastination and poor self-concept. To counter this cycle, the present study makes use of gratitude journals. In a study conducted by Lin (2015) on young adults, strong connections between self-esteem and gratitude were established.

\section{METHODOLOGY}

\section{Objective}

The objective of the present study is to understand the nature and level of procrastination among the Indian youth and then make appropriate, need-based interventions for participants with high levels of procrastination. It focuses on the aspect of enhancing well-being to deal with procrastination through interventions such as mindfulness techniques, introspection, maintaining a gratitude journal etc.

\section{Hypothesis}

The research hypothesis for this study is that the level of procrastination can be reduced among individuals whose procrastination level has increased during the Covid-19 induced lockdown through mindfulness and other appropriate interventions.

\section{Participants}

Individuals belonging to the age group of 17-25 years were eligible to respond to the procrastination scale and only those participants were selected for further interventions, whose score on the procrastination scale increased during the COVID-19 pandemic induced lockdown. The total number of participants that filled the scale was 109, out of which 27 were selected for further interventions based on the inclusion criteria out of which 19 were females and 8 were males. The sampling method used in this study was convenient purposive sampling. 


\section{Countering The Rise in Covid-19 Related Procrastination: An Intervention Study}

\section{Material}

Lay's (1986) General Procrastination Scale was originally a 36-item true-false inventory for academic tasks which was later converted to the present 20 item scale that examines procrastination across a variety of everyday tasks. The inventory uses a 5-point scale for scoring ranging from, 1 i.e., False to 5 i.e., True.

The inventory was used to measure procrastination before the lockdown and during the lockdown to select participants for interventions and later, the GPS was administered again to measure the procrastination score once the intervention schedule was completed.

The scale has demonstrated high reliability and validity as demonstrated by a number of studies which calculated a Cronbach alpha of .78 (Ferrari, 1991), .82 (Lay, 1986) etc.

\section{Data Collection}

The questionnaire was administered through the online mode using a google form version of the GPS which they all filled at their convenience.

\section{Scoring}

The General Procrastination Scale is a 5-point Likert scale. The scale has 20 items out of which scores for item number 3, 4, 6, 8, 11, 13, 14, 15, 18 and 20 are reverse scored. The scores of each item are then totaled to obtain the final procrastination score.

\section{Procedure}

After the selection of the participants who had shown a rise in the level of procrastination during the lockdown, the interviews were conducted through telephonic conversations and video conferencing after which the intervention was conducted for a period of three weeks with at least one activity scheduled per day. The participants were sent the activities according to the schedule, which had to be completed in the specified time frame of 24 hours. The interventions were administered in the following manner:

Table 1: Schedule of Intervention

\begin{tabular}{|l|l|}
\hline Week & Activities \\
\hline Week 1 & Activity 1-8 \\
\hline Week 2 & Activity 9-16 \\
\hline Week 3 & Activity 17-23 \\
\hline
\end{tabular}

As the last stage of evaluation, participants were again asked to fill the General Procrastination Scale and exit interviews were conducted.

\section{Data}

Table 2: Responses on Lay's General Procrastination Scale

\begin{tabular}{|c|c|c|}
\hline $\begin{array}{l}\text { Total number of } \\
\text { responses }\end{array}$ & $\begin{array}{l}\text { Respondents } \\
\text { increased levels } \begin{array}{r}\text { with } \\
\text { of } \\
\text { procrastination during } \\
\text { lockdown }\end{array}\end{array}$ & $\begin{array}{l}\text { Percentage of respondents } \\
\text { with increased } \\
\text { procrastination } \\
\text { lockdown }\end{array}$ \\
\hline 109 & 67 & $61.5 \%$ \\
\hline
\end{tabular}


Countering The Rise in Covid-19 Related Procrastination: An Intervention Study

Table 3: Individual responses on Lay's General Procrastination Scale before and after the intervention

\begin{tabular}{|c|c|c|}
\hline Participants & $\begin{array}{l}\text { Procrastination level during } \\
\text { lockdown }\end{array}$ & $\begin{array}{l}\text { Procrastination level after } \\
\text { intervention }\end{array}$ \\
\hline Participant 1 & 69 & 61 \\
\hline Participant 2 & 67 & 62 \\
\hline Participant 3 & 51 & 36 \\
\hline Participant 4 & 58 & 45 \\
\hline Participant 5 & 58 & 55 \\
\hline Participant 6 & 71 & 40 \\
\hline Participant 7 & 49 & 30 \\
\hline Participant 8 & 66 & 53 \\
\hline Participant 9 & 74 & 47 \\
\hline Participant 10 & 55 & 43 \\
\hline Participant 11 & 67 & 62 \\
\hline Participant 12 & 73 & 53 \\
\hline Participant 13 & 49 & 48 \\
\hline Participant 14 & 58 & 33 \\
\hline Participant 15 & 58 & 49 \\
\hline Participant 16 & 65 & 50 \\
\hline Participant 17 & 55 & 45 \\
\hline Participant 18 & 59 & 46 \\
\hline Participant 19 & 70 & 45 \\
\hline Participant 20 & 61 & 33 \\
\hline Participant 21 & 37 & 33 \\
\hline Participant 22 & 68 & 57 \\
\hline Participant 23 & 58 & 49 \\
\hline Participant 24 & 62 & 47 \\
\hline Participant 25 & 78 & 59 \\
\hline
\end{tabular}

(c) The International Journal of Indian Psychology, ISSN 2348-5396 (e) | ISSN: 2349-3429 (p) | 620 
Countering The Rise in Covid-19 Related Procrastination: An Intervention Study

\begin{tabular}{|l|l|l|}
\hline Participant 26 & 55 & 40 \\
\hline Participant 27 & 79 & 58 \\
\hline
\end{tabular}

\section{RESULTS}

Table 4: Mean and Standard Deviation for all participants

\begin{tabular}{|c|c|c|c|c|}
\hline $\begin{array}{l}\text { Pre } \\
\text { intervention } \\
\text { (P1) }\end{array}$ & $\begin{array}{l}\text { Post } \\
\text { intervention } \\
\text { (P2) }\end{array}$ & $\begin{array}{l}\text { P2-P1 } \\
\text { (Difference) }\end{array}$ & Difference - M & \begin{tabular}{|l} 
Square \\
Deviation
\end{tabular} \\
\hline 69 & 61 & -8 & 6.48 & 42.01 \\
\hline 67 & 62 & -5 & 9.48 & 89.9 \\
\hline 51 & 36 & -15 & -0.52 & 0.27 \\
\hline 58 & 45 & -13 & 1.48 & 2.19 \\
\hline 58 & 55 & -3 & 11.48 & 131.82 \\
\hline 71 & 40 & -31 & -16.52 & 272.86 \\
\hline 49 & 30 & -19 & -4.52 & 20.42 \\
\hline 66 & 53 & -13 & 1.48 & 2.19 \\
\hline 74 & 47 & -27 & -12.52 & 156.71 \\
\hline 55 & 43 & -12 & 2.48 & 6.16 \\
\hline 67 & 62 & -5 & 9.48 & 89.9 \\
\hline 73 & 53 & -20 & -5.52 & 30.45 \\
\hline 49 & 48 & -1 & 13.48 & 181.75 \\
\hline 58 & 33 & -25 & -10.52 & 110.64 \\
\hline 58 & 49 & -9 & 5.48 & 30.05 \\
\hline 65 & 50 & -15 & -0.52 & 0.27 \\
\hline 55 & 45 & -10 & 4.48 & 20.08 \\
\hline 59 & 46 & -13 & 1.48 & 2.19 \\
\hline 70 & 45 & -25 & -10.52 & 110.64 \\
\hline 61 & 33 & -28 & -13.52 & 182.75 \\
\hline 37 & 33 & -4 & 10.48 & 109.86 \\
\hline 68 & 57 & -11 & 3.48 & 12.12 \\
\hline
\end{tabular}

(c) The International Journal of Indian Psychology, ISSN 2348-5396 (e)| ISSN: 2349-3429 (p) | 621 
Countering The Rise in Covid-19 Related Procrastination: An Intervention Study

\begin{tabular}{|l|l|l|l|l|}
\hline 58 & 49 & -9 & 5.48 & 30.05 \\
\hline 62 & 47 & -15 & -0.52 & 0.27 \\
\hline 78 & 59 & -19 & -4.52 & 20.42 \\
\hline 55 & 40 & -15 & -0.52 & 0.27 \\
\hline 79 & 58 & -21 & -6.52 & 42.49 \\
\hline & & M:- -14.48 & & S: 1698.74 \\
\hline
\end{tabular}

Table 5: Mean, Standard Deviation, t-calculated, $d f, p$ and hypothesis

\begin{tabular}{|l|l|l|l|}
\hline & Mean & SD & t \\
\cline { 1 - 3 } During lockdown & 61.851 & 9.678 & \multirow{2}{*}{$* *_{-} 9.30$} \\
\cline { 1 - 3 } After intervention & 47.370 & 9.377 & \\
\hline
\end{tabular}

*For calculations refer to the Appendix C

There was a significant effect on the level of procrastination, $\mathrm{t}(26)=-9.30, \mathrm{p}=0.001$, before intervention $(\mathrm{M}=61.851, \mathrm{SD}=9.678)$ as compared to after intervention $(\mathrm{M}=47.370, \mathrm{SD}=$ 9.377). Research hypothesis is thus accepted.

Figure 1: Graph depicting the change in procrastination before and after intervention

\section{Before and After Interventions}

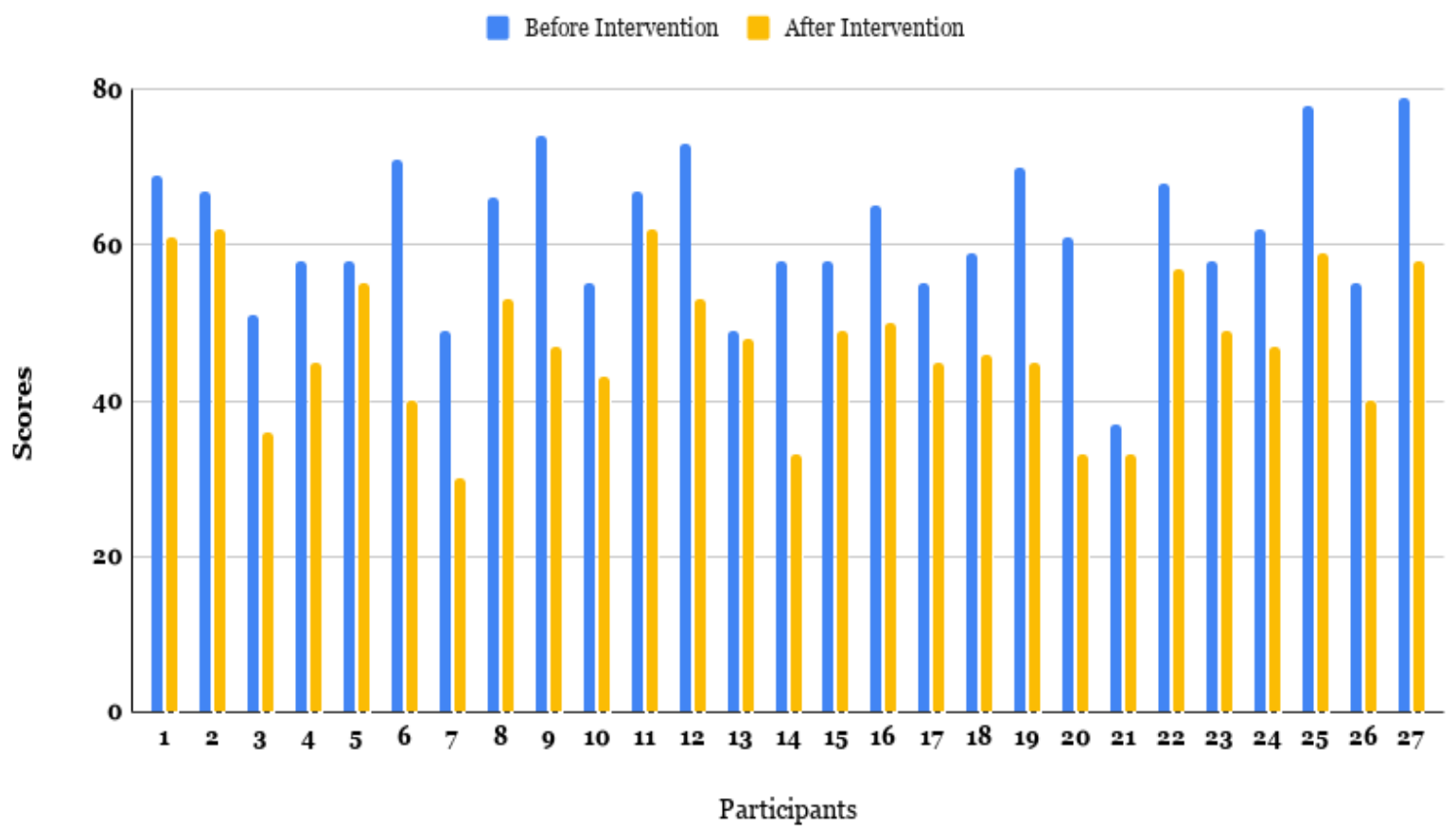

(C) The International Journal of Indian Psychology, ISSN 2348-5396 (e)| ISSN: 2349-3429 (p) | 622 
DISCUSSION

The aim of the present study was to psycho-educate individuals and equip them with mechanisms that can be used for tackling procrastination. The research hypothesis stated that the interventions would lead to a decrease in the levels of procrastination. The results of the study verified the research hypothesis.

As per the data in Data table 2, 61.5\% of the respondents have shown a significant increase in the level of procrastination during the Covid-19 lockdown. Post the intervention period, the outcomes of the study gave $100 \%$ results, that is, all participants showed a decrease in the level of procrastination. This suggests that the interventions deployed in this study are efficient in dealing with questions of procrastination and well-being. Data table 3 depicts that procrastination scores of all the 27 participants reduced after the interventions, proving the efficacy of the methods. Data table 5 suggests that the interventions are significant beyond 0.001 level. The results are in accordance with the study conducted by Cheung et al. (2019) which proved an inverse relation between procrastination and mindfulness. Qualitative and quantitative data shows that procrastination and physical activity are inversely related as established by the study conducted by Codina, Pestana, Valenzuela, et al. (2020).

The activities which were appreciated the most included mindfulness and gratitude journals. The reason for this was attributed to the level of calm and focus that increased for not some, but almost all the participants. Certain participants who also had their university exams during the course of this intervention reported that these interventions significantly helped them calm their nerves down, sleep well, and focus substantially on their studies. It was also ensured that the participants are not overburdened due to the activities and have enough time for their other tasks. The participants reported that the gratitude journals encouraged them to be introspective and give substantial thought to what they felt. The questions were to help them identify their source of happiness, inspiration, and everything good around them. The participants gave substantial time to these questions before penning down their thoughts. Reminiscing about their good deeds and thinking about what makes them happy also brought a sense of positivity in their thoughts and gave a small boost to their self-esteem, which is hindered due to procrastination as proved by Ferrari (1993). Using the backing by Lin (2015), a couple of gratitude journals were given to the participants. The participants reported that they felt good about themselves and felt more motivated to do things because they acknowledged their positives. A participant also reported that she felt more creative because of the interventions, her creative block cleared due to the gratitude journal and mindfulness activities. This has also been supported by Milgram's study in 1988 according to which, individuals who feel capable and more motivated are able to do more work.

The study had certain limitations. The sample of participants may not be representative of the population as the method of convenient purposive sampling was followed due to Covid19 restrictions. The study was conducted in an online mode, thus the level of interactions was not what they could have been in an offline study. This did not allow the researchers to read body language or establish a better rapport with the participants. Another limitation was that 7 participants dropped out of the study due to prior commitments. However, the study still had 27 participants thus, it did not affect the study or the results majorly. Lastly, three participants had their exams during the duration of the intervention, which can be a confounding variable hence hindering the results of the study. However, these participants reported to be calmer during their exams as compared previously and were able to manage 


\section{Countering The Rise in Covid-19 Related Procrastination: An Intervention Study}

their time well. They also reported that since they slept well due to meditation, they were able to wake up on time and study as well.

The study aims to counter the rise of procrastination in the current, extremely trying environment. The scope of this study transcends beyond the lockdown since procrastination is something human beings may face due to the advent of stress, major changes in life, monotony and so much more. Since these interventions don't require a clinician, they can be self-administered at one's own will. Another advantage of using such interventions is that they have no negative side effects, adding to the efficacy of the intervention. The greater aim of this study is to act as an impetus for larger studies to carry out similar interventions at larger scales to help more people feel better in terms of self-concept, well-being, and motivation. Rather than just serving the youth, mindfulness and other interventions can also help caregivers during a pandemic situation to give themselves 5 minutes out of the 24 hours to feel calmer and more collected. These interventions have no age, gender, class boundaries and do not require expensive resources either. The impact of such a study has no bounds and people can be encouraged to do them at an unprecedented time like this lockdown due to the pandemic.

\section{CONCLUSION}

The study focuses on the increase in levels of procrastination in individuals during the Covid-19 induced lockdown. During the course of the study, the authors aim to understand the nature and level of procrastination through different perspectives. The study works at reducing the individuals' level of procrastination using interventions such as mindfulness techniques, introspection, maintaining a gratitude journal etc.

\section{REFERENCES}

Chen, B., Shi, Z., \& Sun, S. (2017). Life history strategy as a mediator between childhood environmental unpredictability and adulthood personality. Personality and Individual Differences, 111, 215-219. Doi: https://doi.org/10.1016/j.paid.2017.02.032

Cheung, R. Y., \& Ng, M. C. (2019, January). Being in the moment later? Testing the inverse relation between mindfulness and procrastination. Personality and Individual Differences, 141, 123-126. Doi: https://doi.org/10.1016/j.paid.2018.12.015

Codina, N., Pestana, J. V., Valenzuela, R., et al (2020, May). Procrastination at the Core of Physical Activity (PA) and Perceived Quality of Life: A New Approach for Counteracting Lower Levels of PA Practice. International Journal of Environmental Research and Public Health. 17(10), 3413. https://doi.org/10.3390/ijerph17103413

Dionne, F. (2016, July). Using acceptance and mindfulness to reduce procrastination among university students: Results from a pilot study. Revista Prâksis, 1, 8-20. Doi: https://doi.org/10.25112/rp.v1i0.431

Ferrari, J. R., Johnson, J. L., \& McCown, W. G. (1995). Procrastination and task avoidance: Theory, research, and treatment. Springer Science \& Business Media.

Lodha P, Sharma A, D'souza G, Marathe I, D'souza S, Rawal S, Pandya V, Sousa AD. (2019). General Procrastination Scale: Development of Validity and Reliability. Int J Med Public Health. 2019;9(3):74-80.

DOI: http://dx.doi.org/10.5530/ijmedph.2019.3.19

Milgram, N. A., Gehrman, T., \& Keinan, G. (1992). Procrastination and Emotional Upset: A Typological Model. Personality and Individual Differences. 13(12), 1307-1313. https://doi.org/10.1016/0191-8869(92)90173-M 


\section{Countering The Rise in Covid-19 Related Procrastination: An Intervention Study}

Sirois, F.M., Tosti, N. (2012, December). Lost in the Moment? An Investigation of Procrastination, Mindfulness, and Well-being. J Rat-Emo Cognitive-Behav Ther 30, 237-248. https://doi.org/10.1007/s10942-012-0151-y

\section{Acknowledgement}

To Dr. Shyamolima Ghosh Choudhury and Dr. Poonam Phogat Department of Psychology, Gargi College, University of Delhi and to all those who participated in the study to facilitate the research process, we extend our heartfelt gratitude.

\section{Conflict of Interest}

The author(s) declared no conflict of interest.

How to cite this article: Ghosh Choudhury S., Ananya, Katoch S. \& Tanishqa (2021). Countering The Rise in Covid-19 Related Procrastination: An Intervention Study. International Journal of Indian Psychology, 9(3), 616-627. DIP:18.01.060.20210903, DOI: $10.25215 / 0903.060$

\section{Appendix A}

\begin{tabular}{|c|c|c|}
\hline S. No. & Activity & Date \\
\hline 1 & Mindful Breathing & 15th March \\
\hline 2 & Sound Meditation & 15th March \\
\hline 3 & $\begin{array}{l}\text { TedTalk - Inside the Mind of a Master } \\
\text { Procrastinator by Tim Urban }\end{array}$ & 16th March \\
\hline 4 & Physical Activity - Standing Workout & 17th March \\
\hline 5 & Meditation & 18th March \\
\hline 6 & Body Scan & 19th March \\
\hline 7 & Gratitude Journal & 20th March \\
\hline 8 & Positive Affirmations & 21st March \\
\hline 9 & Breathing Colors & 22nd March \\
\hline 10 & Sound Meditation & 22nd March \\
\hline 11 & $\begin{array}{l}\text { TedTalk - The Surprising Habits of an Original } \\
\text { Thinker by Adam Grant }\end{array}$ & 23rd March \\
\hline 12 & Physical Activity - Happy Dance & 24th March \\
\hline 13 & Breathing Colors & 25th March \\
\hline 14 & Listing Tasks & 25th March \\
\hline 15 & Being a procrastinator worksheet & 26th March \\
\hline
\end{tabular}


Countering The Rise in Covid-19 Related Procrastination: An Intervention Study

\begin{tabular}{|l|l|l|}
\hline 16 & Mindful Eating & 28th March \\
\hline 17 & Covey's Time Management Quadrant & 30th March \\
\hline 18 & $\begin{array}{l}\text { TedEd- Try Something New for 30 days by } \\
\text { Matt Cutts }\end{array}$ & 31st March \\
\hline 19 & Reflective Questions & 1st April \\
\hline 20 & Sound Meditation & 2nd April \\
\hline 21 & Embrace who I am questionnaire & 3rd April \\
\hline 22 & Questionnaire & 3rd April \\
\hline 23 & Interviews & 4th April \\
\hline
\end{tabular}

\section{$\underline{\text { Appendix B }}$}

\section{During lockdown}

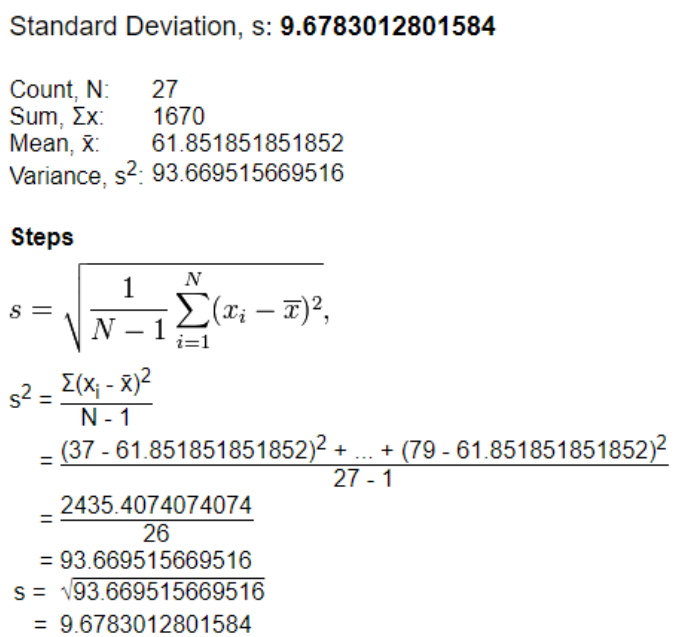

\section{After Interventions}

Standard Deviation, s: $\mathbf{9 . 3 7 7 3 3 8 2 6 4 9 0 6 1}$

Count, N: 27

Sum, $\Sigma x: \quad 1279$

Mean, $\bar{x}: \quad 47.37037037037$

Variance, $s^{2}: 87.934472934473$

Steps

$s=\sqrt{\frac{1}{N-1} \sum_{i=1}^{N}\left(x_{i}-\bar{x}\right)^{2}}$,

$\mathrm{s}^{2}=\frac{\Sigma\left(\mathrm{x}_{\mathrm{i}}-\overline{\mathrm{x}}\right)^{2}}{\mathrm{~N}-1}$

$=\frac{(30-47.37037037037)^{2}+\ldots+(62-47.37037037037)^{2}}{27-1}$

$=\frac{2286.2962962963}{26}$

$=87.934472934473$

$\mathrm{s}=\sqrt{87.934472934473}$

$=9.3773382649061$

(c) The International Journal of Indian Psychology, ISSN 2348-5396 (e) | ISSN: 2349-3429 (p) | 626 
Countering The Rise in Covid-19 Related Procrastination: An Intervention Study

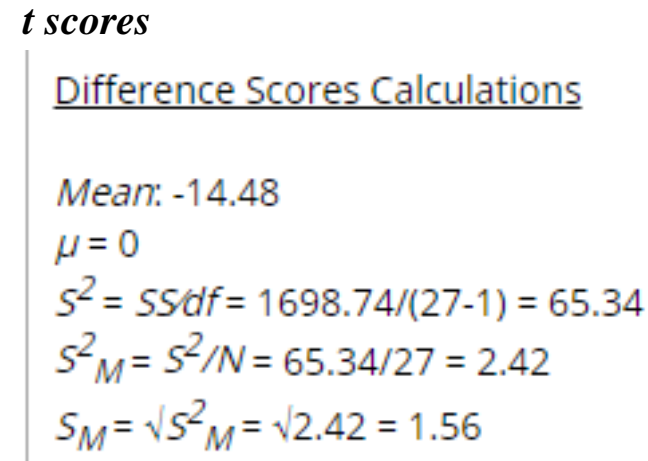

$\underline{\text { T-value Calculation }}$

$t=(M-\mu) / S_{M}=(-14.48-0) / 1.56=-9.31$ 